\title{
Iniciação científica: percepção do interesse de acadêmicos de odontologia de uma universidade brasileira
}

\section{Scientific initiation: the perception of academic interest of dentistry of a Brazilian university}

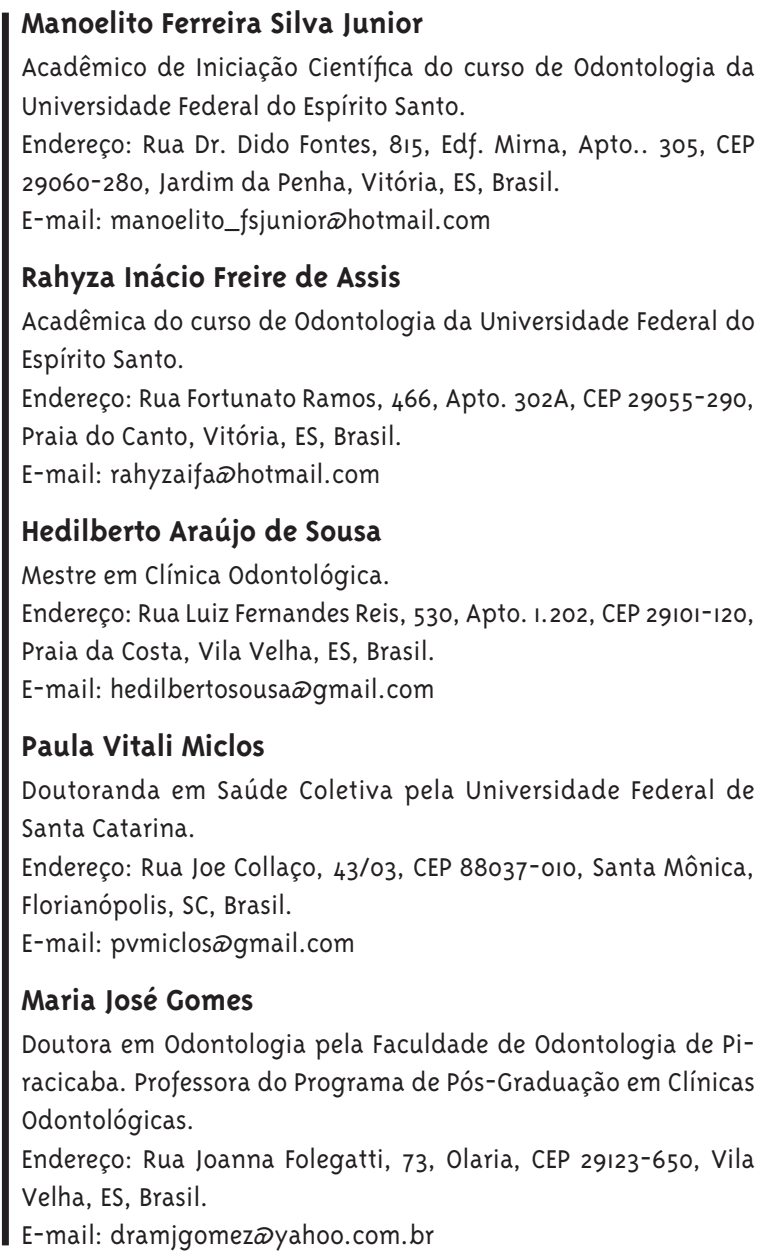

E-mail: dramjgomez®yahoo.com.br

\section{Resumo}

A iniciação científica é uma oportunidade aos acadêmicos de desenvolver senso crítico, ético e profissional, com o intuito de aumentar a evidenciação científica e conduzir o que de melhor a prática odontológica pode oferecer. A universidade é um cenário importante de estímulo e incentivo à pesquisa, tendo um papel fundamental no desenvolvimento desta atividade, sendo necessário o apoio institucional e de professores interessados. O objetivo é conhecer o interesse dos graduandos do curso de Odontologia da Universidade Federal do Espírito Santo em relação à pesquisa científica. 0 estudo se caracteriza como descritivo transversal com abordagem quanti/ qualitativa. A coleta de dados foi realizada com 101 acadêmicos do curso de Odontologia da Universidade Federal do Espírito Santo (UFES) através de um questionário semiestruturado, pré-validado, contendo perguntas sobre o interesse em pesquisa, participação em jornadas científicas e sobre o Trabalho de Conclusão de Curso (TCC). Os resultados encontrados foram: 79,2\% relatam gostar de pesquisa científica e $81,19 \%$ têm interesse em pesquisar. É principalmente no $3^{\circ}$ e $4^{\circ}$ períodos que os alunos começam a frequentar eventos científicos, e na sua maioria, no $5^{\circ}$ e $6^{\circ}$ períodos começam a elaborar e apresentar trabalhos científicos. Conclui-se que um número considerável de acadêmicos de Odontologia mostra interesse e participa de pesquisas científicas, mesmo que a falta de incentivo financeiro, apoio dos professores e da infraestrutura não colabore para a realização de estudos com maior evidência científica.

Palavras-chave: Academias e Institutos; Metodologia; Educação superior; Educação em Odontologia. 


\section{Abstract}

Undergraduate research is an opportunity for students to develop critical, ethical and professional thought, in order to increase the scientific disclosure and conducts in accordance to the best dental practice available. The university is an important scenario where to stimulate and encourage research, playing a key role in the development of this activity; for that, institutional support and interested teachers is necessary. The objective of this research is to know the interest of undergraduate students of Dentistry at the Federal University of Espirito Santo regarding scientific research. The study is characterized as a cross-sectional, quantitative / qualitative approach. Data collection was conducted with 101 students of Dentistry at Federal University of Espirito Santo (UFES) through a semi-structured, pre-validated questionnaire, including questions about the interest in research, participation in scientific conferences and Graduation Monography. The results were: $79.2 \%$ reported liking for scientific research and has $81.19 \%$ interest in research. It is mainly in the 3 rd and 4 th periods that students begin to attend scientific meetings, and mostly on the 5 th and 6 th period begin to prepare and present scientific papers. It is concluded that considerable number of dental students shows interest and participate in scientific research, in spite of the lack of financial incentive, teacher support and infrastructure, which do not facilitate the conduction of studies collecting more scientific evidence.

Keywords: Academies and Institutes; Methods; Education; Higher; Education; Dentistry.

\section{Introdução}

A Conferência Mundial sobre Ensino Superior realizada pela Organização das Nações Unidas para a Educação, a Ciência e a Cultura (UNESCO) em Paris, no ano de 1998 teve uma importante conclusão que pode ser resumida em apenas uma frase: "Não há condições de uma Nação querer ser moderna com desenvolvimento social e econômico se não tiver base científica e tecnológica" (Fava-de-Moraes e Fava, 200o, p. 73). Assim, a valorização e incentivo às pesquisas científicas, cada vez mais cedo, é uma necessidade mundial.

A Iniciação Científica (IC) pode ser definida como um processo no qual é fornecido o conjunto de conhecimentos indispensáveis para iniciar o jovem nos ritos, técnicas e tradições da ciência. Nessa perspectiva, o conceito de IC foi construído no interior das universidades brasileiras como uma atividade realizada durante a graduação, na qual o aluno inicia a ciência e vivencia experiências vinculadas a um projeto de pesquisa, elaborado e desenvolvido sob a orientação de um docente (Simão e col., 1996).

Associar conhecimento teórico às técnicas práticas com o intuito de reproduzir os procedimentos estabelecidos e consolidados, foi por muito tempo o necessário para a formação dos cirurgiões-dentistas, assim eram restritos e pouco incentivados para elaborar e desenvolver trabalhos de cunho científico visando o desenvolvimento de um povo, uma área, ou uma profissão. Atualmente a área científica está sendo um dos requisitos necessários de diferencial entre os acadêmicos e principalmente na inserção destes na profissão (Tachibana e col., 2004).

Anteriormente correlacionava-se a prática de trabalhos científicos aos interessados em exercer a docência, no entanto, essa percepção tem sido mudada e torna-se cada vez mais praticada pelos acadêmicos, devido à visão de que os resultados científicos auxiliam diretamente na sua conduta clínica. Uma evidência disso é a propagação e expansão de uma nova abordagem clínica, denominada de Odontologia Baseada em Evidência que trata a prática clínica não mais calcada em "receitas de bolo", mas sim, de uma abordagem para a tomada de decisão na área de saúde na qual o clínico utiliza a melhor 
evidência disponível, em sintonia com os anseios do paciente, para decidir qual é a melhor alternativa de tratamento para cada paciente (Faber, 2008). Sendo esta, fundamentada na experiência clínica, na Bioestatística, e na Informática aplicada à área da saúde e alicerçada numa nova forma de pensar a ciência (Ribeiro e col., 2009).

A iniciação científica permite que o aluno de graduação tenha noções teóricas e metodológicas de pesquisa, buscando incentivar-lhe a capacidade de pensar e o espírito questionador. Esse contato com a pesquisa, além de enriquecer a formação profissional do graduando, fornece-lhe o alicerce para a continuidade dos estudos nos programas de pós-graduação, principalmente se a opção feita for a carreira acadêmica (Pereira e col., 1999). Além disso, a atividade de pesquisa na graduação é importante para desenvolver o espírito crítico e a competência para buscar respostas aos problemas da prática profissional (Gomes e Sanna, 2004).

A pesquisa e o desenvolvimento científico encontram na universidade seu habitat por excelência. Para Mendes (1991), uma das grandes perspectivas da pesquisa desenvolvida no meio universitário consiste exatamente em poder voltar-se para as reais necessidades da sociedade brasileira como um todo, com cunho altamente comunitário, visando ao bem-estar de todos e à melhoria da qualidade de vida.

Conhecer o público-alvo e quais são as perspectivas de adequação e interesse no meio científico é a melhor forma de saber quais medidas podem ser adotadas para maior participação dos acadêmicos de Odontologia. Apenas sabendo suas motivações e suas dificuldades, poderemos concluir como proceder e aumentar a quantidade e principalmente a qualidade dos estudos realizados.

\section{Metodologia}

O presente trabalho é um estudo transversal, descritivo com abordagem quantitativa e qualitativa. A população do estudo foi composta por 101 acadêmicos do curso de Odontologia, desde os ingressos (1o período) aos egressos ( $9^{\circ}$ período), devidamente matriculados no semestre 2011/1. Os critérios de inclusão da pesquisa foram: acadêmicos devidamente matriculados no semestre letivo de 2011/1, possuir mais de 18 anos e ter assinado o Termo de Consentimento Livre e Esclarecido (TCLE).

Os dados foram coletados através da aplicação de um questionário semiestruturado composto por questões abertas e fechadas, validado por meio de pré-teste com 10 alunos de outro curso da mesma instituição de ensino. A análise de dados quantitativos foi realizada através do programa Microsoft Excel 2010. As questões qualitativas foram analisadas e categorizadas seguindo o Conteúdo de Bardin (2002), buscando abarcar, dentro da perspectiva da fenomenologia, o relato específico de cada estudante e, posteriormente, o conjunto da amostra.

Esta pesquisa foi aprovada pelo Comitê de Ética em Pesquisa da Universidade Federal do Espírito Santo (CEP-UFES) sob o protocolo de número 031/10.

\section{Resultados e discussão}

Este estudo foi constituído por uma amostra de conveniência com público-alvo composto por acadêmicos do curso de Odontologia, composto por 101 $(37,4 \%)$ acadêmicos de Odontologia da Universidade Federal do Espírito Santo (UFES), distribuindo-se entre os sexos, em $65(64,35 \%)$ mulheres e $36(34,65 \%)$ homens. A idade dos acadêmicos participantes da pesquisa variou de 18 a 26 anos, com média relativa de 20,69 anos. Observou um percentual mais elevado de indivíduos do sexo feminino na composição da amostra estudada, corroborando com estudos de Neder (2001), o que não foi considerado como fator significativo nos resultados da pesquisa.

Os resultados quantitativos estão apresentados na forma de números absolutos e relativos, ilustrados através de tabelas. As respostas qualitativas, dentre as diversas e diferentes falas dos alunos, foram categorizadas em três grupos: aspecto positivo, aspecto negativo e ambivalente, os quais exemplificam bem o pensamento dos acadêmicos quanto ao assunto abordado.

A maioria dos acadêmicos do curso de Odontologia da UFES afirma gostar de pesquisa, e quando foram perguntados sobre o interesse na área, o resultado foi ainda mais expressivo do que os que gostam, mostrando que mesmo que os alunos não gostem, acham necessário para o seu conhecimento e desenvolvimento técnico-científico (Tabela 1). 
Tabela I - Número e proporção (\%) de acadêmicos segundo conhecimentos gerais sobre pesquisa científica

\begin{tabular}{|c|c|c|c|c|}
\hline & \multicolumn{2}{|c|}{$\operatorname{sim}$} & \multicolumn{2}{|c|}{ Não } \\
\hline & $n$ & $\%$ & $\mathrm{n}$ & $\%$ \\
\hline Gosta de pesquisar? & 80 & 79,2 & 21 & 20,8 \\
\hline Tem interesse em pesquisar? & 82 & 81,19 & 19 & 18,81 \\
\hline Frequenta eventos científicos? & 62 & 61,39 & 39 & 38,61 \\
\hline Pretende exercer a docência? & 38 & 37,62 & 63 & 62,38 \\
\hline Lê artigos científicos? & 84 & 83,17 & 17 & 16,83 \\
\hline Possui currículo Lattes? & 77 & 76,24 & 24 & 23,76 \\
\hline Sabe o que é Programa Institucional de Iniciação Científica (PIIC)? & 72 & 71,29 & 29 & 28,71 \\
\hline
\end{tabular}

Alguns relatos sobre a importância de pesquisar estão expressos a seguir:

\section{Aspecto positivo:}

A pesquisa é importante para achar ou descobrir coisas novas, que podem ajudar para o avanço na área da saúde e em Odontologia em particular.

Para ter um bom currículo.

Porque as pesquisas contribuem com a prática clínica, trazendo inovações.

Em resumo, os alunos afirmaram que acham importante pesquisar, devido ao conhecimento que é sedimentado a partir dessa forma de desenvolvimento acadêmico. Além disso, é uma forma de melhorar o currículo e interesse em entrar em cursos de pós-graduação, principalmente o mestrado e dourado, posteriormente. Acrescenta-se também a vontade de ir além dos livros e apenas reproduzir metodologias já utilizadas, mas inovar e evoluir com novos conhecimentos para o seu meio profissional e consequentemente para a sociedade em geral. Ninguém se opôs à importância da pesquisa no seu desenvolvimento acadêmico.

Oliveira e colaboradores (2008) afirmam que múltiplos fatores podem contribuir para o desempenho dos estudantes. Além de critérios socioeducativos, culturais e econômicos dos alunos, outros devem ser considerados, como a qualificação docente, logística e organização do curso, estrutura curricular e integração ensino-serviços de saúde, por exemplo. No entanto, destacamos, especialmente, a participação desses alunos em atividades de pesquisa, nas instituições em que estudam, como fator relevante no processo de ensino-aprendizagem.
Os congressos, simpósios, palestras, constituem um cenário de oportunidades para o enriquecimento da aprendizagem e conhecimento, além da possibilidade da divulgação de pesquisas e exposição de temas pertinentes à área de estudo, bem como em áreas afins, sendo estes primordiais na vida do acadêmico, bem como do profissional, já que a Odontologia, como uma ciência, evolui sempre, e cabe ao profissional estar atualizado e agregar valores à prática clínica. Pouco mais da metade dos pesquisados afirmaram já ter participado de algum evento científico, sendo um número pouco expressivo pela importância dessas atividades na vida acadêmica e posteriormente dos profissionais de saúde.

Quando perguntados sobre o porquê acham importante frequentar congressos, as respostas foram:

\section{Aspecto positivo:}

Adquirir conhecimentos e ter oportunidade de mostrar trabalhos.

Para que o estudante/profissional se mantenha atualizado dentro da sua profissão.

\section{Aspecto negativo:}

Não vou ser professor, e no consultório onde trabalharei, não precisarei.

\section{Ambivalente:}

Enriquecer o currículo.

Ainda não fui, pois acho necessário ter uma base de conhecimento acadêmico para frequentá-los.

$\varepsilon$ É importante frequentar para atualização e aprender mais, mas não é necessário. 
Aos que opinaram, a palavra atualização é motivadora para a participação dos acadêmicos nos congressos, ou em qualquer outra atividade científica. Muitos afirmam ser de extrema necessidade, uma vez que a evolução da Odontologia tem-se feito muito rápida, e eles devem estar cientes das novas tendências do curso. Mas alguns relatam que mesmo sendo importante, não veem como necessário frequentá-los.

Enriquecer o currículo, conhecer novas áreas, sedimentar o conhecimento, conhecer palestrantes com amplos estudos, parecem também ser outros motivos peculiares para atrair os acadêmicos. Mazon e Trevizan (2001) em seu estudo fala que no mundo contemporâneo, cuja composição se dá pela chamada sociedade da informação, estamos cada vez mais buscando novos conhecimentos para nos adequar a este contexto, objetivando puramente a realização pessoal ou visando melhores oportunidades no competitivo mercado de trabalho.

Quando perguntados sobre o interesse em ser docente, muitos acadêmicos $(35,64 \%)$ se interessam, embora desmistificam o fato de gostar e ter interesse em pesquisa como associação à carreira docente. Hoje as universidades federais do Brasil estão em ampla expansão, com grande número de contratações, e o que tem exigido um maior número de professores, assim como qualidade profissional, estabelecidos por melhor formação, através dos cursos de especialização, mestrado, doutorado e vários outros adicionais que complementam o seu currículo. Por todos esses motivos, a iniciação científica é um grande apoio a estes que pretendem seguir a carreira acadêmica, fazendo trabalhos na sua área de interesse, criando linhas de pesquisas. Entretanto fica expresso que não são apenas para os futuros docentes que a iniciação científica deve ser alcançada, afinal, muito dos resultados dessa pesquisa irão inferir na conduta clínica e em procedimentos mais seguros e confiáveis para o paciente.

Quando perguntados sobre a frequência de leitura de artigos científicos, as respostas foram diversas, mas em resumo foram:

\section{Aspecto positivo:}

Com frequência.

\section{Aspecto negativo:}

Não leio

Raramente

\section{Ambivalente:}

Sempre que acho interessante.

Quando há necessidade para trabalhos e pesquisa.

Os acadêmicos não se mostraram muito adeptos à leitura de artigos científicos, e a grande maioria afirmou somente ler durante as aulas devido aos trabalhos curriculares, o que leva a deduzir que são obrigados a ler artigos, exclusivamente, por nota. A média de leitura de artigos por semestre não ultrapassou 05 artigos, um número pouco expressivo para um curso da ciência da saúde.

O currículo Lattes mostrou-se bastante utilizado na vida acadêmica desses alunos pesquisados, o que confirma uma preocupação destes na formação de um currículo com suas informações acadêmicas e profissionais.

Com relação ao conhecimento da existência do Programa Institucional de Iniciação Científica (PIIC), a maioria dos alunos afirmou saber do que se trata o programa.

Tabela 2 - Número e Proporção (\%) de acadêmicos segundo respostas dadas à pergunta: Acha a pesquisa científica um diferencial em qual aspecto?

\begin{tabular}{cccccccc}
\multicolumn{2}{c}{ Acadêmico } & \multicolumn{2}{c}{ Profissional } & \multicolumn{2}{c}{ Ambos } & \multicolumn{2}{c}{ Nenhum } \\
$n$ & $\%$ & $n$ & $\%$ & $n$ & $\%$ & $n$ & $\%$ \\
\hline 10 & 9,9 & 3 & 2,97 & 83 & 82,18 & 5 & 4,95 \\
\hline
\end{tabular}

Na Tabela 2, os acadêmicos foram questionados a respeito do diferencial que eles vêem nos alunos que realizam pesquisas científicas, sendo que uma minoria com menos de $5 \%$ afirmou que não vê nenhum benefício, mas a ampla maioria afirmou ver um ganho tanto durante a vida acadêmica, quanto na vida profissional. Isso mostra que os acadêmicos sabem da importância de pesquisar, mesmo os que não participam, estão cientes do ganho que é/seria estar engajado em projetos científicos durante a faculdade. 
Aos acadêmicos que já realizaram algum tipo de pesquisa, foram-lhes feitos alguns questionamentos, tais como:

Sobre o que os influenciou a pesquisarem, cujas respostas foram:

\section{Aspecto positivo:}

Certificado e adquirir mais conhecimento

Mercado de trabalho, pretendo fazer mestrado e doutorado e isso pode ajudar.

Pois quero conhecer todas as áreas e as possibilidades de mercado de trabalho e carreiras a ser seguidas

Os próprios alunos que pesquisam

Muita curiosidade.

Ter experiência em iniciação científica.

Os professores.

\section{Ambivalente:}

Perspectiva de bolsa.

Aos alunos que pesquisam, entre suas motivações estão a obrigação de se fazer o Trabalho de Conclusão de Curso (TCC), a curiosidade, a perspectiva de se ganhar uma bolsa, os próprios professores que procuram alunos que possam ajudar a desenvolver e ampliar suas linhas de pesquisas. Até mesmo os alunos que já pesquisam se tornam um exemplo, e contribuem para que outros alunos também queiram participar.

Sobre as dificuldades encontradas na realização da pesquisa, os alunos relataram:

\section{Aspecto negativo:}

Teтpo.

Falta de artigos disponíveis online de graça.

Verba para pesquisa.

Conseguir material e local adequado.

\section{Ambivalente:}

Escrever o projeto.

Análise de dados.

Coleta de dados

A falta de tempo foi o problema mais elencado, o que leva a crer que seja o maior vilão das pesquisas realizadas na instituição de ensino para os acadêmicos de Odontologia. Posteriormente, aparece a falta de respaldo econômico, seguido pela pouca infraestrutura que impossibilita de realizar alguns tipos de estudo. Um outro problema enfatizado foi com relação à orientação dos professores pesquisadores. Oliveira e colaboradores (2008) também mostram que os maiores desafios estão na inexistência de pessoal capacitado e com tempo disponível para orientação de trabalhos, carência de estrutura física e falta de estímulo institucional.

Foram questionados se houve alguma dificuldade em conseguir professor-orientador:

\section{Aspecto negativo:}

Achar professor disponivel

E perguntados se o orientador deu suporte necessário:

\section{Aspecto negativo:}

Não deu suporte necessário.

Pouca assistência.

Esses questionamentos fizeram com que chegássemos à conclusão de que o número de professores envolvidos é insuficiente para o número de acadêmicos interessados, o que traz uma sobrecarga de trabalho aos professores que se dedicam à pesquisa $\mathrm{e}$ também gera insatisfação até mesmo para os alunos, pois não têm o subsídio e o apoio necessários para orientar em todas as fases da pesquisa.

Um número considerável de acadêmicos se sente satisfeito apenas com o conhecimento adquirido

Tabela 3 - Número e proporção $(\%)$ de acadêmicos segundo respostas dadas à pergunta: Pretende continuar estudando após a graduação?

\begin{tabular}{cccccccccc} 
& Não & & \multicolumn{2}{c}{ Especialização } & \multicolumn{2}{c}{ Mestrado } & \multicolumn{2}{c}{ Doutorado } & \multicolumn{2}{c}{ PhD } \\
$n$ & $\%$ & $n$ & $\%$ & $n$ & $\%$ & $n$ & $\%$ & $n$ & $\%$ \\
38 & 37,62 & 63 & 62,37 & 31 & 30,7 & 17 & 16,83 & 15 & 14,85 \\
\hline
\end{tabular}


durante o curso de graduação e afirma não pretender realizar nenhum tipo de curso de pós-graduação. A maioria, 62,37\%, quer ingressar nos cursos de pós-graduação, e a porcentagem de interessados diminui à medida que há o aumento do nível de titulação proponente em relação ao tempo de estudo, com 30,7\% no mestrado, $16,83 \%$ no doutorado e $14,85 \%$ que pretendem chegar até a livre-docência. Os resultados mostram que nem todos os que querem fazer curso de mestrado, doutorado e livre docência, necessariamente, também tenham interesse em realizar uma especialização, antes ou após o curso de mestrado. Com esse número elevado de interessados nos cursos de pós-graduação, um bom currículo parece ser uma forma de aumentar as chances de aprovação. Para isto, espera-se um amplo interesse e dedicação por parte destes acadêmicos na realização de pesquisas (Tabela 3).

\section{Tabela 4 - Número e proporção $(\%)$ de acadêmicos segundo respostas dadas às perguntas relativas às Infor- mações gerais sobre o Trabalho de Conclusão de Curso (TCC)}

\begin{tabular}{lcccc} 
& \multicolumn{2}{c}{ Sim } & Não & n \\
& $n$ & $\%$ & 78 & 77,22 \\
Já começou a pensar no tema do TCC? & 23 & 22,78 & 83 & 82,18 \\
Já começou a desenvolver o TCC? & 18 & 17,82 & 73,27 & 27 \\
O seu TCC foi/será seu único projeto de pesquisa? & 74 & 10,89 & 90 \\
Pretende publicar artigo cujo tema seja o mesmo do seu TCC? & 11 & & 89,11 \\
\hline
\end{tabular}

O trabalho de conclusão de curso parece ser um problema aos acadêmicos, pois a ampla maioria ainda não tem ideia do que pretende realizar no trabalho final da graduação. Para a maioria dos alunos, essa é a única atividade científica que eles realizam. Sua obrigatoriedade, retira a escolha por pesquisa, o que confronta com os resultados de interesse em pesquisa. Poucos alunos pretendem levar o tema do TCC à frente e publicá-lo, mostrando que poucos são os estudos mais aprofundados que gerem publicações posteriores a sua apresentação (produção científica) (Tabela 4).

Quando perguntados sobre a importância do TCC, as justificativas foram:

\section{Aspecto positivo:}

Estimula os alunos a continuarem pesquisando $e$ adquirindo mais conhecimentos para entrarem no mercado de trabalho como profissionais capacitados.

O TCC tem um papel importante na jornada do estudante que tem interesse em continuar estudando após a graduação (mestrado, doutorado, PhD).

Importante para quem quer seguir a carreira de pesquisador.
É importante para demonstrar um pouco do conhecimento que foi adquirido durante o curso.

Creio que seja a forma mais simples de demonstrar parte do conteúdo absorvido durante a vida acadêmica.

\section{Aspecto negativo:}

Passei 5 anos rígidos estudando, não precisa de um trabalho que liga tudo.

Para me formar.

Não acredito que seja necessário o TCC, pois será feito por obrigação, melhor seria se a produção científica fosse feita durante a graduação.

\section{Ambivalente:}

Porque eu não sei, mas todo mundo faz.

É importante tero TCC, mas não consideronecessário.

Por ser obrigatório.

Não há como avaliar o nível do aluno com um trabalho apenas

Este trabalho terá a finalidade de iniciar uma linha de pesquisa para a pós-graduação.

Faz com que os acadêmicos saibam pesquisar $e$ avaliar os artigos 
Da forma como é feito não acrescenta muita coisa positiva

Sobre a necessidade do TCC, houve uma grande divergência de pensamento: uma linha acha importante para os alunos sedimentarem conhecimentos, forçá-los a realizar um trabalho mais aprofundado e obrigatoriedade em apresentar para uma banca. Já outros acham totalmente desnecessário, pois é apenas mais um trabalho, e que não consegue atingir os seus objetivos. Atualmente os alunos egressos se sentiram muito insatisfeitos com o modo atual de confecção e apresentação do TCC, mas já que a estrutura curricular do curso de Odontologia da UFES foi alterada em 2008, muitos desses aspectos estão sendo modificados e melhorados. Mais uma vez o projeto pedagógico parece ser um grande estimulador do apoio ao TCC, e também cria linhas de pesquisa, para aqueles que pretendem seguir estudando.

Quando perguntados o período que começaram a pensar e pôr em prática o TCC, a maioria dos aca- dêmicos responderam que é a partir do $7^{\circ}$ período, para não deixar muito em cima da hora, e restringir a execução da pesquisa que estejam querendo fazer. Isto traz um melhor resultado, tanto para os acadêmicos que não o fazem na última hora, mas também para os professores orientadores, que têm mais tempo para se dedicarem aos projetos.

Quanto ao tempo que levaram ou pretendem se dedicar à confecção do TCC, o tempo médio que os alunos esperam para realiza-lo é de o6 meses, sendo que alguns necessitam de maior tempo. Uma das alterações na estrutura curricular foi a criação das disciplinas de TCC I e TCC II, para que os alunos sejam melhores conduzidos, e possam pensar em um maior espaço de tempo, sobre o Trabalho de Conclusão de Curso.

Alguns alunos afirmaram já ter exposto a ideia do seu TCC na Jornada Universitária Capixaba de Odontologia (JUNCO) na tentativa de corrigir erros, divulgar sua pesquisa, e para treinar, já que estarão apresentando para uma banca avaliadora.

Tabela 5 - Número e proporção $(\%)$ de acadêmicos segundo respostas dadas à pergunta Informações gerais sobre a Jornada Universitária Capixaba de Odontologia (JUNCO)

\begin{tabular}{lccccc} 
& \multicolumn{3}{c}{ Sim } & \multicolumn{3}{c}{ Não } \\
& $n$ & $\%$ & $n$ & $\%$ \\
\hline Já participou da JUNCO? & 79 & 78,22 & 22 & 21,78 \\
Acha a JUNCO importante? & 63 & 62,38 & 38 & 37,62 \\
Já apresentou na JUNCO? & 27 & 26,73 & 74 & 73,27 \\
\hline
\end{tabular}

Em relação à participação dos estudantes na JUNCO, que ocorre anualmente na própria universidade, realizada pelo centro acadêmico do curso de Odontologia, verificou-se que mesmo com duração de uma semana e aulas suspensas, grande parte dos alunos não frequentam a Jornada, com participação apenas de $65,35 \%$ dos alunos integrantes da pesquisa. Vale ressaltar que os acadêmicos dos primeiros períodos ( (1ํao $3^{\circ}$ período), têm maior resistência à participação da JUNCO, por acharem que ainda não têm subsídio para compreender os temas que serão elucidados (Tabela 5).

Quando perguntados sobre o que motivou ou o que desmotivou os acadêmicos a participarem da
JUNCO, as respostas foram:

\section{Aspecto positivo:}

Meus amigos me motivaram.

Palestras interessantes.

Divulgar minhas pesquisas.

Complementar o meu currículo.

Os cursos e palestras.

Assistir os trabalhos apresentados.

\section{Aspecto negativo:}

Não quis pagar.

Falta de interesse. 


\section{Estudar para seminários e provas}

Para descanso fora de época.

\section{Ambivalente:}

Ganhar certificado.

Deixei de ir pois acho que não tenho conhecimentos suficientes para entender o que foi exposto.

Era necessário para as matérias do período.

Muitos são os motivos para os alunos participarem, desde o convite a professores de renome para dar cursos com temas atuais, à oportunidade de apresentação de trabalhos no formato painel, apresentação oral e mesa demonstrativa. Outro fator é a obrigatoriedade por parte dos professores, como última chance de forçar os alunos a se interessarem pela Jornada, feita pelos e para os acadêmicos de Odontologia. Aparece também o incentivo para melhorar o currículo. Já entre os fatores desmotivadores estão a falta de interesse por parte dos próprios acadêmicos, e outros aproveitam para descansar nessa semana ou fazer outras atividades que sucederão a Jornada.

Também foram perguntados por que é importante ir à JUNCO, e as respostas foram:

\section{Aspecto positivo:}

Traz pesquisadores diversificados, e diferentes projetos atuais.

Importante para os alunos que podem apresentar seus trabalhos e é um aprendizado para quem assiste às apresentações e palestras.

Pois é uma forma diferente e abrangente de estudo. $\varepsilon$ ú uma forma de unir os estudantes do Estado, mostrar o que eles estão produzindo e atualização de temas.

A JUNCO muitas vezes é o primeiro passo para inserir o aluno da UFES no meio científico.

Porque é uma atividade diferente para nós alunos.

Porque traz conhecimento além do que é visto na faculdade.

$03^{0}$ e $4^{\circ}$ períodos parecem ser os de início da participação dos acadêmicos na JUNCO, isso se justifica devido aos períodos antecessores serem compostos por matérias básicas, pouco específicas ao curso de Odontologia, o que gera uma descrença errônea por parte dos alunos, de que não vão aprender muita coisa participando da Jornada.

Quando questionados sobre a importância de não apenas participar, mas de apresentar na JUNCO, as respostas foram:

\section{Aspecto positivo:}

Divulgação de trabalho e ensaio para congressos importantes.

Aprimorar a forma de apresentação.

$\varepsilon$ importante para nosso aprendizado em pesquisas.

Para divulgar o conhecimento adquirido com as pesquisas.

\section{Ambivalente:}

Melhorar o currículo.

Alguns acadêmicos falaram que adequam ou amplificam seus trabalhos que foram expostos na JUNCO, a fim de reapresentá-los em outros congressos, e os principais congressos nos quais estes trabalhos são levados são: o Congresso Internacional de Odontologia de São Paulo (CIOSP) e a Reunião da Sociedade Brasileira de Pesquisa Odontológica (SBPqO).

Durante a preparação, qual a maior dificuldade encontrada desde a preparação até a apresentação do trabalho?

\section{Aspecto negativo:}

Entrevistar os alunos.

Encontrar tempo para ler artigos e fazer a pesquisa.

As normas para apresentação de trabalho.

Colocar o trabalho no tempo adequado para apresentação.

A falta de mais informação e ajuda.

No entanto, foi-nos possível observar que alguns bolsistas de iniciação científica estão insatisfeitos, devido à sobrecarga de tarefas que lhes são atribuídas, desvinculadas, muitas vezes, dos objetivos propostos pelos programas a que estão vinculados (Nogueira, 1982).

$05^{\circ}$ e 6ํㅜ períodos são os de maior número de adeptos à pesquisa, sem relação com o TCC, pois os acadêmicos começam a ter as matérias mais especí- 
ficas do curso, curiosidade e, até mesmo, pela oportunidade de participar do Programa Institucional de Iniciação Científica (PIIC), principalmente obter bolsa. Também como motivação para a pesquisa, vem a melhor formação acadêmica, com maior ênfase em uma área de interesse pessoal.

\section{Conclusão}

- Em termo geral, os acadêmicos de Odontologia mostram-se interessados e consideram positiva a área de pesquisa. A falta de incentivo financeiro, infraestrutura e tempo impedem um melhor desenvolvimento e dedicação por parte dos alunos, já que o curso é integral, e demanda muito tempo do aluno.

- A JUNCO é, para a grande maioria dos acadêmicos de Odontologia da UFES, o primeiro contato destes com o meio científico, e assim apontam a sua necessidade como sendo fonte de conhecimento, e também para despertar o interesse daqueles que ainda não participam de iniciação científica, além de possuir cursos que abordam temas atuais e relevantes à formação profissional do acadêmico.

- Em relação ao TCC, a maioria dos acadêmicos afirma atribuir-lhe extrema importância, mas infelizmente, estes só colocam em prática sua elaboração no último período acadêmico e, por falta de tempo, geram estudos com baixo teor científico. Com a finalidade de resolver este problema, o curso de Odontologia da UFES resolveu incluir mais uma disciplina na sua estrutura curricular, um ano antes do término do curso.

- A visão reducionista do interesse em pesquisa restrito aos acadêmicos que pretendem seguir carreira docente não se mostrou com grande impacto neste grupo, sendo um fator importante, pois os resultados gerados por essas pesquisas têm influenciado cada vez mais a vida clínica, e fortalece a Odontologia Baseada em Evidência, o que gera um maior número de adeptos, e de formadores de opinião.

\section{Referências}

BARDIN, L. Análise do conteúdo. Lisboa: Edições 7O, 2002.
FABER, J. Odontologia baseada em evidências: o fundamento da decisão clínica. Revista Dental Press Ortodontia e Ortopedia Facial, Maringá, v. 13, n. 1, p. 5, 2008. Editorial.

FAVA-DE-MORAES, F.; FAVA, M. A iniciação científica: muitas vantagens e poucos riscos. São Paulo em Perspectiva, São Paulo, v. 14, n. 1, p. 7377, 2000.

GOMES, M. M. F.; SANNA, M. C. A pesquisa em enfermagem no congresso de iniciação científica de uma universidade de São Paulo. Revista Brasileira de Enfermagem, Brasília, DF, v. 57, n. 5, p. 574-578, 2004.

MAZON, L.; TREVIZAN, M. A. Fecundando o processo da interdisciplinaridade na iniciação científica. Revista Latino-Americana de Enfermagem, Ribeirão Preto, v. 9, n. 4, p. 83-87, 2001.

MENDES, I. A. C. Pesquisa em enfermagem: impacto na prática. São Paulo: EdUSP, 1991.

NEDER, R. T. A iniciação científica como ação de fomento do CNPq: o Programa Institucional de Bolsas de Iniciação Científica - PIBIC. 2001. Dissertação (Mestrado em Desenvolvimento Sustentável) - Universidade de Brasília, Brasília, DF, 2001.

NOGUEIRA, M. J. C. A pesquisa em enfermagem no Brasil: retrospectiva histórica. Revista da Escola de Enfermagem da USP, São Paulo, v. 16, n. 1, p. $17-26,1982$.

OLIVEIRA, N. A.; ALVES, L. A.; LUZ, M. R. Iniciação científica na graduação: o que diz o estudante de medicina? Revista Brasileira de Educação Médica, Rio de Janeiro, v. 32, n. 3, p. 309-314, 2008.

PEREIRA, L. O.; INOCENTI, A.; SILVA, G. B. A iniciação científica na graduação em enfermagem da Universidade de São Paulo (1993 a 1996): análise crítica. Revista Latino-Americana de Enfermagem, Ribeirão Preto, v. 7, n. 3, p. 77-86, 1999.

RIBEIRO, R. A. et al. Relatórios dos simpósios realizados no $39^{\circ}$ Encontro do Grupo Brasileiro de Professores de Ortodontia e Odontopediatria em Curitiba/PR. Pesquisa Brasileira em Odontopediatria e Clínica Integrada, João Pessoa, v. 9, n. 1, p. 125-133, 2009. 
SIMÃO, L. M. et al. O papel da iniciação científica para a formação em pesquisa na pós-graduação. In: SIMPÓSIO DE PESQUISA E INTERCÂMBIO CIENTÍFICO DA ASSOCIAÇÃO NACIONAL DE PESQUISA E PÓS-GRADUAÇÃO EM PSICOLOGIA - ANPEPP, 6., 1996, Rio de Janeiro. Anais... Rio de Janeiro: ANPEPP, 1996, p. 111-113.

TACHIBANA, M.; PAVANI, R.; BARIANI, I. C. D.

Participação em eventos científicos e formação do universitário. Psico, Porto Alegre, v. 35, n. 1, p. 8996, 2004. 